\title{
Digital Marketing for Arts and Culture Enterprises
}

\author{
Marija Valcic \\ University of Applied Science Baltazar, V. Novaka 23, 10290 Zapreši \\ Croatia \\ marija.valcic@bak.hr \\ Duško Ljuština \\ Satirical Theatre Kerempuh Zagreb, Ilica 31, 10000 Zagreb \\ Croatia \\ dusko.ljustina@kazalistekerempuh.hr \\ Ivan Simunic \\ Zadar Country, B. Petranovia 8, 23000 Zadar \\ Croatia \\ simunic6@gmail.com
}

ABSTRACT: As marketers, we know when looking at the 4 Ps of marketing (product, place, price and promotion) that by far product is the most impactful on box office revenue. In an attempt to adapt to the worsening economic environment, some theaters began to program "safer" seasons and increased ticket prices to drive more revenue. Many adopted models looked far more similar to Broadway than the regional theater just a few years prior. We don't say this to be judgmental, only to illustrate that desperate times required desperate measures for some.

Marketing and communications for arts and culture organizations were once less complicated than today. Just ten to fifteen years ago, most arts and culture organizations focused marketing strategies and tactics on traditional print and radio advertising campaigns for single ticket sales, brochure mailings, and telemarketing for subscription and membership campaigns. This was supplemented by standard public relations outreach in the form of press releases for each program, production, exhibit or even.

Keywords: Digital Marketing, Digital Communication, Digital Arts

Received: 12 October 2018, Revised 5 January 2019, Accepted 18 January 2019

DOI: $10.6025 / \mathrm{jdp} / 2019 / 9 / 2 / 37-39$

(C) 2019 DLINE. All Rights Reserved

\section{Introduction}

Is digital a part of your marketing mix? Today, it should be. For arts and culture organizations, digital marketing represents the opportunity to analyze marketing campaigns and understand what is working, and what is not, in real-time. The onesize- fits-all approach is dead. Long live tailor-made solutions! 
If an organization does not yet have a digital marketing plan, it is not alone. Using digital marketing without a specific plan is common across all industry sectors. Yet without a plan, insufficient resources will hamper efforts from the onset. Many arts and culture organizations have not yet established digital marketing plans that prioritize opportunities, detail costs and account for the use of both external and internal resources [1]. For some, digital marketing was tacked onto traditional marketing or public relations programs without full consideration of the use or abuse of resources, or most importantly, without measureable results in mind. Adequate planning to develop a consistent and increasingly sophisticated program was also neglected. How that is in Croatia?

It had been "just enough" in the past to add a Facebook page here or a digital ad there without fully examining the potential for each opportunity. Many organizations also applied digital marketing across the board without analyzing cost-of-sale and potential returns, ignoring new channels and tactics that are foundational to effective campaigns [2]. When approaching digital marketing or fine-tuning an existing plan, organizations should consider these three elements as part of a larger strategy.

\section{Retargeting}

Website analytics offer a wealth of information to arts and culture organizations. Have you wondered how many people come into contact with a website and are not "converted" into a stakeholder: a volunteer, a donor, a ticket buyer? The answer is probably close to 90 percent. It is rare that visitors to websites find what they need and progress to the next step of connecting with a volunteer coordinator, making a donation or buying a ticket in one visit [3]. Retargeting is an approach that keeps your organization's brand top-of-mind by frequent advertising. It can bring visitors back to finish what they started in the first place. For example, when a visitor abandons a shopping cart for a music festival, he or she will see recurring ads for that organization on Facebook or YouTube. Today, organizations can use their website's behavioral data to serve ads to people who have visited their websites to achieve a range of objectives - retargeting them to purchase a ticket, make a donation or redeem benefits. However, it is not the equivalent of digitalized buys. Retargeting serves personalized ads to only those people who have visited a site in search of precise information - from within other sites, apps and programs. Truly, retargeting is the newest form of direct marketing.

Retargeting also offers metrics to assist an organization in directing its digital marketing plan. If an organization does not have internal expertise in this area, there are a number of local and national companies that can help prioritize effective campaigns within a range of budget.

\section{Social Media}

It is universally acknowledged that social media is a powerful tool for arts and culture organizations. Few sectors of the nonprofit industry lend themselves more easily or more intuitively to the social sphere. With platforms such as Instagram, Facebook, Twitter, Pinterest, YouTube and Vine, organizations can generate significant exposure for their causes and brands [9]. Consider the following when fine-tuning a social media program: Avoid the common hazard of trying to be everywhere, engaged and active on all social media platforms and broadcasting identical content through all channels. Evaluate the resources invested in current platforms and determine which are more effective based on priority objectives. Research new options and select the social media platforms that strongly engage the typical stakeholder. Learn where prospects and current stakeholders are already spending time and meet them there.

Do not forget about human resources. Some organizations misjudge the time required to manage social media. Assigning new social media channels to an already busy marketing or public relations manager, without a thoughtful dialogue, will inevitably result in weak outcomes. While social media is $24 / 7$, employees are not. Consider that every social media initiative requires a team with the right training and expertise to position it for success. And, if an organization does not have a social media policy in place that applies to all employees, set a goal to establish one at the beginning. Social media also enables organizations to listen to what stakeholders are saying, while monitoring what issues are trending within stakeholder communities. By listening, organizations can remain current with concerns that are important to those they serve, well beyond geographic boundary.

\section{Content Marketing}

Content marketing is the creation of content ranging from blogs and articles, to videos and news releases, which has value for audiences. This free content is a tool to convert prospects into stakeholders and engages them with an organization's mission.

\begin{tabular}{llllll}
\hline 38 & Journal of Data Processing Volume & 9 & Number 2 & June & 2019 \\
\hline
\end{tabular}


For arts and culture organizations, content marketing can be a springboard to connect with stakeholders in multiple ways, inform key demographics, foster dialogue and build relationships. Well-written content that has value can spread virally across social networks as it is shared, generating powerful word-of-mouth [4]. Before examining an organization's content marketing program, consider the following: Do staff have the time, training and expertise required to create excellent content? Is the organizational mindset prepared for fast turnaround times and open to sharing ideas? If the answer is no to either of these questions, this is an opportunity to review processes and policies that create roadblocks to advancing a content marketing program [5].

Self-promotion, for example, is a particular offshoot of content creation that is worth mentioning here. People do not want advertising; they want valuable and interesting "insider information" that illustrates relevancy [6]. People want to engage with organizations and causes they care about; they appreciate the opportunity to build a relationship.

\section{Optimizing Digital Marketing Example Croatia}

While using electronic media to promote programs or market performance is nothing new, the tools and scope of digital marketing are constantly in flux. Smart organizations focused on optimizing earned revenues know that digital marketing offers options for targeting, retargeting, testing and tailoring messages [7]. However, it is a challenge for arts and culture organizations to determine where, how and when to invest limited resources in this channel — and how to maximize staff time for even greater returns [8]. Establish priorities, create a plan, make a calendar, measure results and adjust campaigns, as needed. The "Kerempuh" Theater uses all available distribution channels, in order to communicate with the audience, writers, directors, actors, critics and others. Already $62 \%$ of public buys on line tickets [7].

\section{Conclusion}

Arts and culture organizations have the opportunity and the challenge to connect with audiences and stakeholders through a growing number of channels. More than just engaging with key audiences, organizations can, and must constantly, tap into the wealth of data now available to adjust their plans in-progress. With firm goals in-hand, an organization can more easily navigate the adoption of digital marketing that synchronizes with its mission, vision and values and achieves results $[8,9]$.

\section{References}

[1] Brown. C. (2007). The complete guide to Google advertising. United States: Atlantic Publishing.

[2] Cannings. C. 7 Key benefits of blog marketing. 2013. Available: http://www.streetdirectory.com/travel_guide/113659/blogging/ 7_key_benefits_to_blog_marketing_for_your_business.html.

[3] Chaffey, D., Ellis-Chadwick, F. (2012). Digital Marketing: Strategy, Implementation and Practice. 5 ed. Harlow: Pearson Education Ltd. 2012.

[4] GHI 2009, Advantages of Using LinkedIn for Professional Networking [Online] Available at: http://www.greenhostit.com/ company/green-blog/96-social-media/336-linkedinadvantages-business-networking)

[5] Katina, B. (2013). The Advantages of Webinar. 2013. Available: http://www.ehow.com/list_7495125_advantages-webinar.html.

[6] Lusted, M. (2011). Social Networking. Minnesota: ABDO Publishing. 2011.

[7] Satiri ko Kazalište Kerempuh: Internimaterijaliza 2014-2015. godine.

[8] Sigfusson, T., Chetty, S. (2013). Building international entrepreneurial virtual networks in cyberspace. Journal of World Business 48, p. 260-270.

[9] WPPCM 2011 (2011). The Advantages of Pay Per Click Advertising. 2011 [Online] Available at: http://www.webrageous.com/ blog/pay-perclick-advertising-advantages 